\section{JOURNAL OF THE SOUTH AFRICAN} INSTITUTION OF CIVIL ENGINEERING

Vol 57 No 4, December 2015, Pages 20-29, Paper 1236

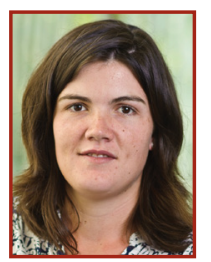

PHIA SMIT, who is a member of the South African Institution of Civil Engineering (SAICE), received her BEng in Civil Engineering from the University of Pretoria in 2012. This paper is based on her research done for her Master's at the University of Pretoria. Her field of interest is concrete technology.

\section{Contact details:}

Department of Civil Engineering

University of Pretoria

Pretoria

0002

South Africa

T: $+27(0) 124202429$

E:phia9006@gmail.com

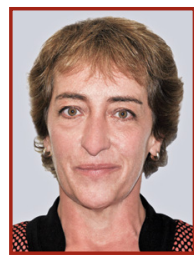

PROF ELSABÉ KEARSLEY graduated with a degree in Civil Engineering from the University of Pretoria in 1984, and she holds a PhD from the University of Leeds. She worked as a structural design engineer in both South Africa and the United Kingdom before becoming a staff member at the University of Pretoria. She was the 2009 President of the South African Institution of Civil Engineering (SAICE) and she is currently the Head of the Department of Civil Engineering at the University of Pretoria. For the last 23 years she has been involved with cement and concrete materials research.

\section{Contact details:}

Department of Civil Engineering

University of Pretoria

Pretoria

0002

South Africa

T: $+27(0) 124202179$

E: elsabe.kearsley@up.ac.za

\title{
Effect of paste content on the properties of high-strength concrete pavements
}

\author{
M S Smit, E P Kearsley
}

Ultra-thin continuously reinforced concrete pavement (UTCRCP) is an innovative pavement type that has the potential to fulfil South Africa's pavement repair strategy requirements. Premature failure in UTCRCP is linked to the formation of cracks that allow water ingress into supporting layers. Environmental conditions, as well as concrete properties, determine the concrete cracking tendency. Concrete properties are a function of the mixture proportions, and unlike environmental conditions, mixture proportions are controllable. The effect of mixture proportions on the properties of high-strength concrete (HSC) used in UTCRCP should be investigated.

The objective of this research was to study the influence of paste content on the properties of HSC used in UTCRCP. Two sets of concrete were tested. The paste content of the first set was varied from $23 \%$ to $37 \%$ by mass, using multivariable analysis in conjunction with superplasticiser (SP) dosage. The paste content of the second set was varied from $25 \%$ to $60 \%$ by mass, only varying SP dosage to control the workability.

The multivariable analysis revealed that, within the parameter range tested, paste content influenced early-age properties, but not long-term properties. Through variation of the paste content over a wider range during the second set it was found that paste content does influence both the early-age and long-term properties of HSC. From the results it could be seen that increasing the paste content of HSC generally has a detrimental effect. The paste content of HSC used in UTCRCP should be minimised, while maintaining a reasonable workability.

\section{INTRODUCTION}

Ultra-thin continuously reinforced concrete pavement (UTCRCP) is a developing pavement type and has the potential to fulfil many of South Africa's pavement repair strategy requirements (Kannemeyer et al 2007).

UTCRCP consists of an approximately $50 \mathrm{~mm}$ thin layer of $80 \mathrm{MPa}$ high-strength concrete. It is reinforced continuously with small-diameter ( $5 \mathrm{~mm}$ ), closely spaced, welded deformed steel bar mesh. Research by Kannemeyer et al (2007) showed that UTCRCP is sensitive to the development of cracks large enough to allow moisture ingress. Premature failures occur when moisture deteriorates the pavement substructure, resulting in loss of support in the overlay (SANRAL 2012).

Cracks are formed in concrete when restrained deformation induces tensile stress greater than the tensile strength at the time. Concrete shrinkage and thermal movement both influence the deformation of concrete (Giussani \& Mola 2012). The materials and proportions of materials used in concrete control the deformation of concrete (Neville 1995).

It has been stated by SANRAL (2009) that the mixture proportioning of HSC is one of the main challenges in UTCRCP. The mixture proportioning of $\mathrm{HSC}$ is more complex than normal-strength concrete, because low water/cementitious ratios and a wider variety of materials are used (Zain et al 2005). Workability and strength requirements are the main factors governing the mixture proportions used in concrete. Paste content consists of water, cement and admixtures, and is expressed as a percentage of the total concrete mass or volume. In the mixture proportioning of HSC there is an inclination to increase the paste content to facilitate workability (Alves et al 2004). The high paste content and low water/cementitious ratio of HSC increase its cracking tendency. Crack formation in concrete can be controlled by taking cracking tendency into account during the mixture proportioning process (Khokhar et al 2010).

The objective of this paper is to determine the effect of paste content on the properties of HSC, where the observed trends serve as a starting point for further research in minimising the cracking tendency in UTCRCP by mixture proportioning. The paper presents a literature review, the experimental programme and the analysis of the experimental data. Lastly, conclusions are drawn and recommendations are made.

\section{LITERATURE REVIEW}

Concrete undergoes a combination of loaddependent and load-independent deformation throughout its lifetime, and it is the 


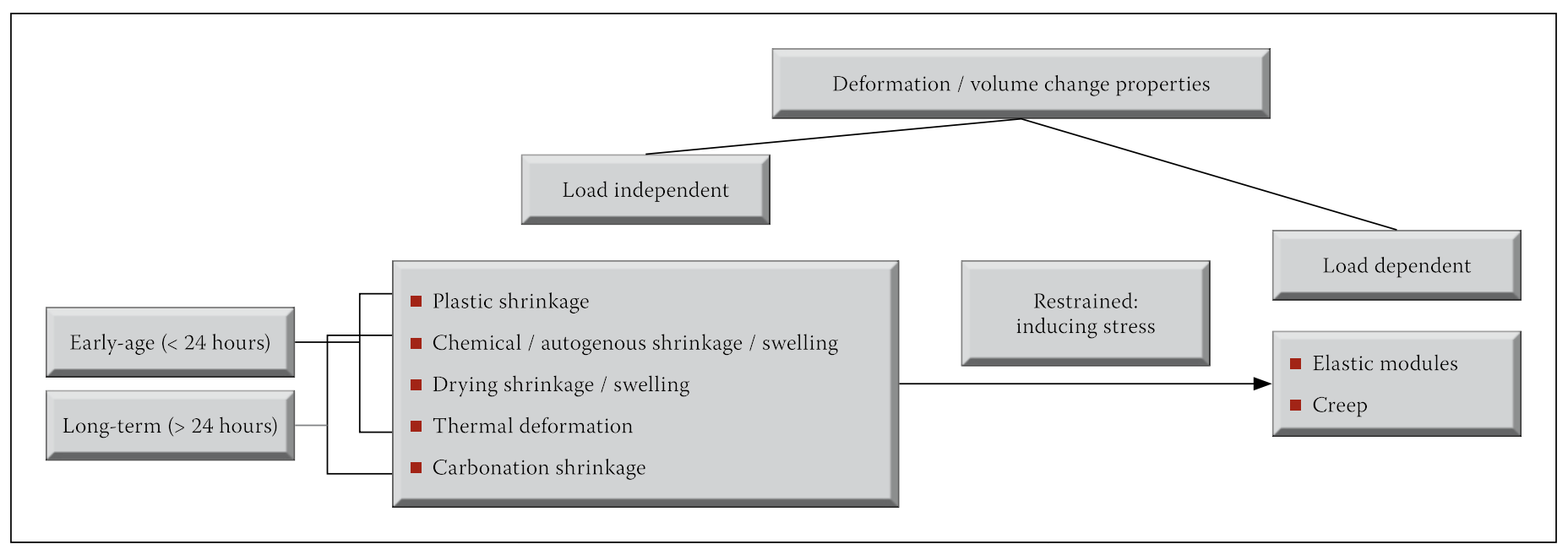

Figure 1 Load-independent and load-dependent deformation properties

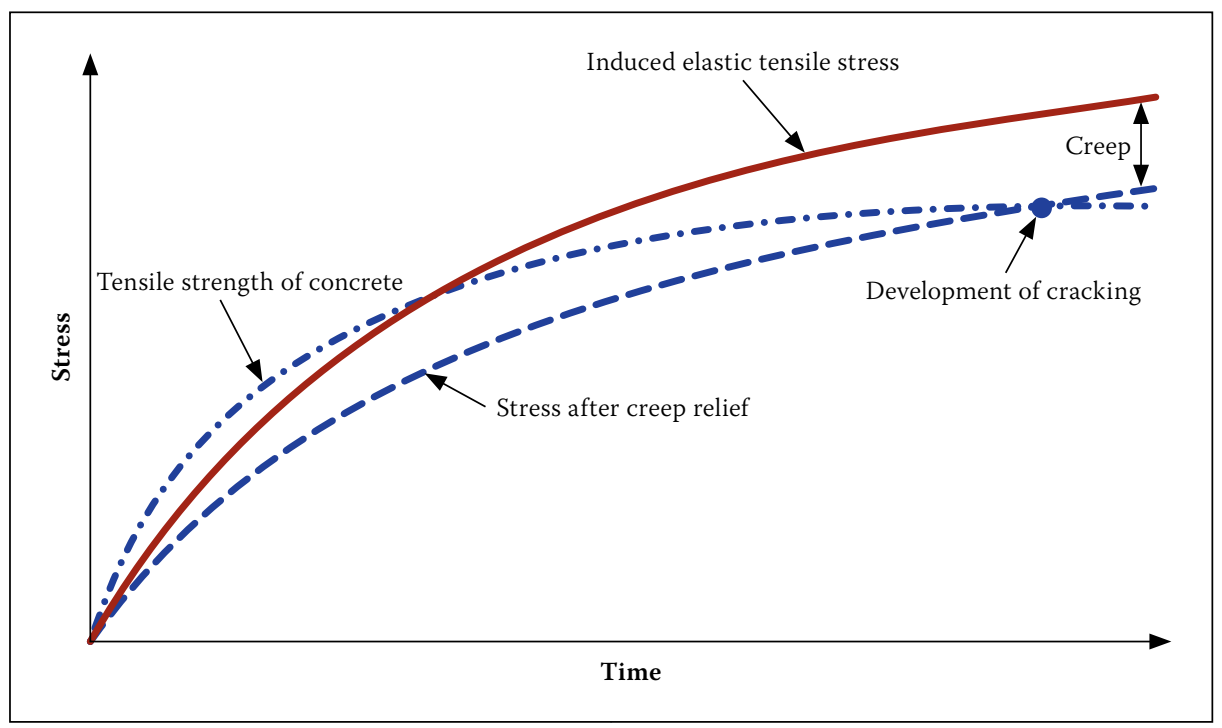

Figure 2 Schematic representation of crack development (Owens 2009)

cumulative contraction and expansion that induces a resultant stress in the presence of restraint. Load-independent deformation includes plastic shrinkage, chemical/ autogenous shrinkage, drying shrinkage, thermal deformation and carbonation shrinkage. Load-dependent deformation consists of elastic strain and creep. Loadindependent deformation is a function of a combination of moisture and temperature effects. Load-independent strains induce stresses when the concrete is restrained, and lead to deformation that is affected by loaddependent deformation. Figure 1 is a schematic diagram which was compiled to clarify the load-dependent and load-independent deformation.

Cracks can start forming in concrete within the first 24 hours (Holt 2001).

Figure 2 is a schematic illustration of crack development in concrete. It shows how a crack develops when the stress exceeds the tensile strength (Owens 2009). Figure 2 also shows how cracking tendency is affected by time. As concrete hardens the tensile strength increases, reducing the cracking tendency, while the modulus of elasticity increases and stress alleviation by creep decreases, increasing the cracking tendency.

HSC mix designs are often described as 'rich' because of their high cement content. The cement content is dependent on the water content, which has the tendency to be high to maintain the workability at low water/cementitious ratios. High cementitious content also ensures high early strength gain (Neville 1995). Conventional mixture proportioning methods have restrictions on the amounts of cement used to limit shrinkage cracking (Neville \& Brooks 2010). These restrictions are not always implemented for HSC. Acceptable cement content ranges between 500 and $550 \mathrm{~kg} / \mathrm{m}^{3}$, while HSC has been made with cement content up to $1000 \mathrm{~kg} / \mathrm{m}^{3}$ (Alves et al 2004).

In a study by Alves et al (2004) the mixture proportions obtained from four methods used to design HSC in Brazil were compared. Three of the four methods showed how the paste content increased as the water/cement ratio decreased. The only method that did not show this tendency was the mix design method based on the particle packing theory. The other mix design methods were a method used for the mix design of normal strength concrete and methods adjusted from normal strength concrete mix design methods for HSC. The research emphasised the tendency of replacing fine aggregate with binder material to maintain workability in HSC. The suitability of a mix was determined by its cost and strength, and the cracking tendency of the mix designs was not taken into account.

The liberation of heat, during the exothermic chemical reaction of cement hydration, causes a temperature rise in the concrete member. The temperature rise is dependent on various factors, including material properties, member geometry and environmental conditions that can be adiabatic or semi-adiabatic (RILEM 1997). Increasing the paste content of a concrete mix would increase the maximum temperature reached due to heat of hydration.

The combination of heat of hydration and thermal expansion can cause cracks (Neville 1995). The temperature of the concrete rises because of heat of hydration. As the heat dissipates, the magnitude of thermal contraction is dependent on the difference between the peak temperature and the ambient temperature. If the concrete is restrained the contraction causes tensile stress in the concrete, because the concrete hardens and gains strength at elevated temperatures. Tensile stresses sufficiently large to crack the concrete can develop (Domone \& Illston 2010).

To obtain high early strength in HSC the cementitious content is often increased while the water/cementitious ratio remains constant (Bentz et al 2011). The effect of the increased paste content on the long-term properties of HSC is not clear, but it has been shown for normal strength concrete that leaner mixes yield higher strengths after only seven days (Singh 1958). Stock et al (1979) found that, at a water/cement ratio of 0.5 , compressive strength decreases 


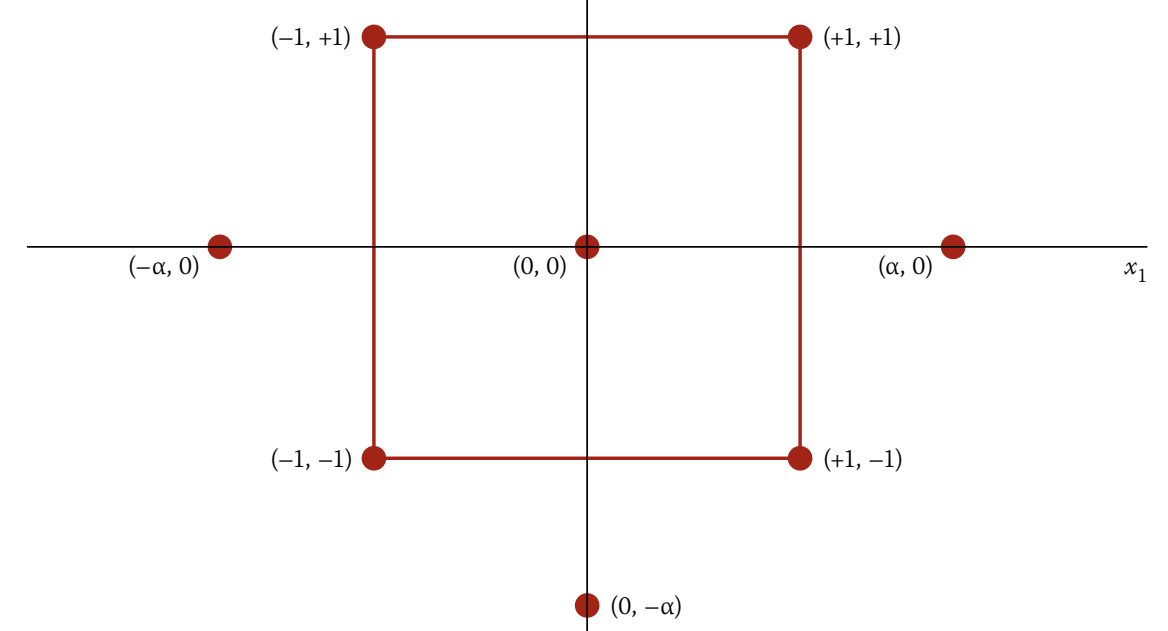

Figure 3 Central composite design with two variables (Montgomery 2001)

as the aggregate content increases from $0 \%$ to $40 \%$ of total volume. With aggregate content exceeding $40 \%$ the compressive strength increases. This phenomenon can be explained by a combination of factors that include reduced total interfacial transition zone area for low aggregate content concrete and reduced porosity of high aggregate content concrete. A similar effect was recorded for the tensile strength of normal strength concrete. Because of the high strength of paste used in HSC concrete, it is possible that the trends found by Stock et al (1979) are not applicable to HSC.

Paste is the volumetrically unstable component of concrete. Deformation properties of concrete are significantly influenced by paste content. Autogenous shrinkage is caused by the withdrawal of water from the capillary pores in the hydrating paste. The magnitude of autogenous shrinkage increases as the water/cementitious ratio decreases. Autogenous shrinkage is important in HSC, because low water/cementitious ratios are used to obtain high strengths. The magnitude of autogenous shrinkage of concrete is also proportional to paste content.

Drying shrinkage is the volumetric contraction of concrete by the removal of water. Concrete with high water/cement ratios contain more water that can be removed from the paste. Similarly concrete with high paste content will also shrink more, due to the overall higher water content. When the aggregate content is increased from approximately $71 \%$ to $74 \%$, drying shrinkage can be reduced by as much as $20 \%$ (Neville 1995).

The relative proportion of paste and aggregate influences the modulus of elasticity of concrete, but it is not usual to find significant variation due to this factor (Gutierrez \& Canovas 1995). Contrary to this, Leemann et al (2011) found that an increase in paste content decreased the modulus of elasticity by as much as $20 \%$ for concrete containing $320 \mathrm{~kg} / \mathrm{m}^{3}$ and $520 \mathrm{~kg} / \mathrm{m}^{3}$ cement at a constant water/cement ratio. Aggregate volume concentration also affects the creep of concrete by restraining the movement of paste. An increase of aggregate content by volume from $65 \%$ to $75 \%$ can decrease creep by $10 \%$ (Neville 1995). Leemann et al (2011) found that concrete with high paste content, such as self-consolidating concrete, exhibits higher creep.

\section{EXPERIMENTAL PROGRAMME}

\section{Response Surface Methodology}

Design of Experiments (DoE) is the strategic planning and execution of experiments to reduce the experimental work required to obtain statistically relevant results. Response Surface Methodology (RSM) is a set of statistical and mathematical techniques (used in DoE) that assist in the modelling and analysis of responses that are influenced by a number of variables. The end goal of RSM is the optimisation of the response (Montgomery 2001).

RSM usually consists of three phases, where phase one focuses on the experimental study, phase two develops the response surface models and phase three uses the statistical models for optimisation (Lotfy et al 2014).

Central Composite Design (CCD) is the RSM design used in this study. CCD is an augmented version of the factorial design with centre points (Stat-Ease Corporation 2014). CCD is useful in RSM, because it makes it possible to develop first- and second-order models.

True functional relationships can be approximated for a small range of variables by polynomials of higher degree. In a second-order model, curvature is represented by interaction and quadratic terms. A central composite matrix does not make it possible to plot a cubic model. Equation 1 is the characteristic form of a second-order model:

$\begin{aligned} y= & \beta_{0}+\sum_{j=1}^{k} \beta_{j} x_{j}+\sum_{i<j} \sum_{i<j} \beta_{i j} x_{i} x_{j} \\ & +\sum \sum_{j=1}^{k} \beta_{j j} x_{j}^{2}+\epsilon\end{aligned}$

where:

$\sum_{j=1}^{k} \beta_{j j} x_{j}^{2}=\underset{\text { quadratic effects of a single }}{\text { variable }}$

$\sum_{i<j} \sum_{i<j} \beta_{i j} x_{i} x_{j}=$ interaction effect between two variables

$\beta_{0}, \beta_{i}, \beta_{i i}, \beta_{i j}=$ regression coefficients $x_{i}, x_{j}=$ investigated factors

$k=$ number of factors

$\epsilon=$ observed noise or error

CCD consists of $2^{k}$ factorial points, $2 k$ axial points and $n$ centre runs. In this context $k$ represents the number of independent variables. Figure 3 shows the three different types of points that define the region of interest for a two-factor design. The factorial points are situated on the corners of the square, the axial points are situated at distance alpha $(\alpha)$ away from the centre point on the negative and positive sides of each axis, and the centre points are situated at the intersection of the two axes.

The quality of prediction of a response surface design is improved when it is rotatable. Whether a response surface design is rotatable is dependent on alpha and the number of centre points. Alpha can be calculated as a function of the number of independent variables. When two independent variables are being tested, alpha will be equal to the radius of a circle fitted on the factorial points that form a square. (Note that the factorial points are also distance alpha away from the centre.) 
Table 1 Materials and material properties

\begin{tabular}{|l|c|}
\hline \multicolumn{1}{|c|}{ Material } & Relative density \\
\hline Cement (52.5 N) & 3.1 \\
\hline Fly ash (unclassified) & 2.2 \\
\hline Condensed silica fume & 2.29 \\
\hline Silica sand & 2.65 \\
\hline 9.5 mm dolomite stone & 2.85 \\
\hline Superplasticiser & 1.065 \\
\hline
\end{tabular}

General Linear Model Analysis of Variance (GLM-ANOVA) is used to determine the influence of a test parameter on the tested response. The higher-order terms that model curvature are excluded to develop a linear model of the response after which the ANOVA of the model is used to evaluate the effect of the test parameters. For a parameter to have a significant influence on a response the $F$-value has to be large and the probability associated with it, the $p$-value, has to be smaller than 0.05 . Lotfy et al (2014) describes the $p$-value as a descriptor of the significance of the parameter on the test results. Similarly, the percentage contribution is a measure of the effect of the independent variables on the response.

\section{Materials}

Table 1 shows the relative density and Figure 4 shows the particle size distribution of the fine materials used in this study. The materials used were selected according to quality and availability. The particle size distribution of silica fume could not be obtained because of the material's tendency to agglomerate in suspension.

\section{Mix design}

The effect of paste content on the properties of HSC was determined using two sets of experiments. For the first set, multivariable analysis was used where the two parameters that control workability (paste content and superplasticiser (SP) dosage) were varied. CCD was used as the response surface design. The concrete set and its results are labelled as Set 1. When response surface design is applied, the range in which the parameters are varied must be such that the resulting concrete mixes must be useable. In using CCD the parameters could not be varied over a very wide range, because the concrete mixes were not allowed to be too dry to compact and the SP dosage was not allowed so high that it would cause segregation.

In the second set of experiments the effect of the paste content was of primary concern and the SP dosage was only varied to ensure good workability for each concrete mix. The base mix design was derived from a published mix design for UTCRCP (Mukandila et al

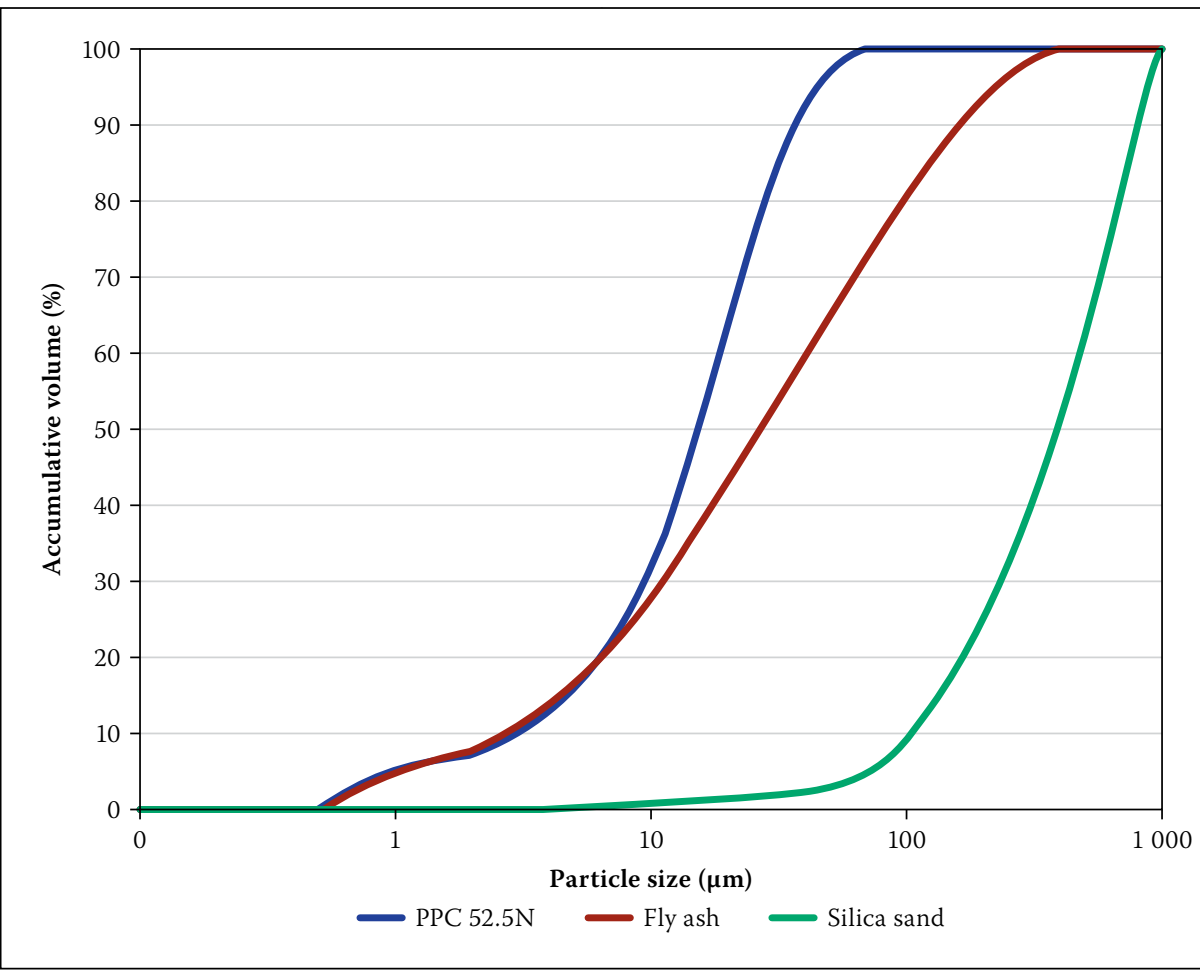

Figure 4 Particle size distribution of used fine materials

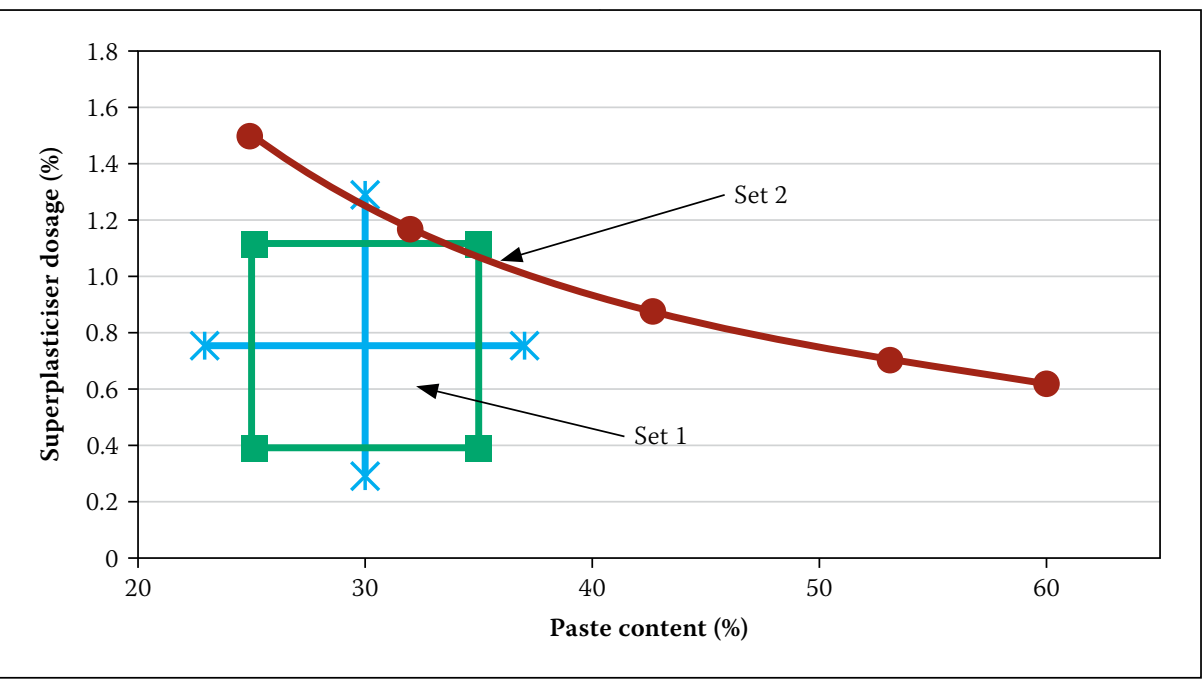

Figure 5 Comparison of range of parameters varied in the two sets of concrete

Table 2 Coded and actual values of varied parameters

\begin{tabular}{|l|c|c|c|c|c|c|c|}
\hline \multirow{2}{*}{ Variables } & \multirow{2}{*}{ Code } & \multirow{2}{*}{ Units } & \multicolumn{5}{|c|}{ Coded variable levels } \\
\cline { 4 - 8 } & & & $-\boldsymbol{\alpha}$ & $-\mathbf{1}$ & $\mathbf{0}$ & $\mathbf{+ 1}$ & $+\boldsymbol{\alpha}$ \\
\hline Paste content & $\mathrm{A}$ & $\%$ & 22.9 & 25 & 30 & 35 & 37.07 \\
\hline SP dosage & $\mathrm{B}$ & $\%$ & 0.238 & 0.388 & 0.75 & 1.112 & 1.262 \\
\hline
\end{tabular}

2009). The concrete set and its results are labelled as Set 2. Figure 5 shows the range over which the parameters were varied for each set of concrete. The paste content is calculated as a percentage of the concrete mass and the SP dosage is calculated as a percentage of the cementitious content, which is all cement, fly ash and silica fume. The target compressive strength was $80 \mathrm{MPa}$.

Thirteen concrete mixes were designed for the CCD response surface modelling where alpha equals the square root of two. As stated, two parameters were varied, paste content (22.9\% to $37.1 \%)$ and SP dosage $(0.238 \%$ to $1.262 \%)$. Table 2 shows the coded and actual values of the variables. Design Expert (Stat-Ease Corporation 2014), commercial software, was used for the statistical evaluation of the results and development of the mathematical models.

The mix designs of Set 1 can be viewed in Table 3 and the mix designs of Set 2 concrete can be viewed in Table 4. Note that the sand content decreased as the paste content increased. 
Table 3 Mix designs of Set 1

\begin{tabular}{|c|c|c|c|c|c|c|c|c|c|c|}
\hline \multirow{3}{*}{$\begin{array}{c}\text { Coded variable } \\
\text { level }\end{array}$} & & $\underset{1}{\operatorname{Mix}}$ & $\begin{array}{c}\operatorname{Mix} \\
2\end{array}$ & $\underset{3}{\operatorname{Mix}}$ & $\begin{array}{c}\operatorname{Mix} \\
4\end{array}$ & $\underset{5}{\operatorname{Mix}}$ & $\underset{6}{\operatorname{Mix}}$ & $\begin{array}{c}\operatorname{Mix} \\
7\end{array}$ & $\begin{array}{c}\operatorname{Mix} \\
8\end{array}$ & $\begin{array}{r}\text { Mix } \\
9-13\end{array}$ \\
\hline & A & -1 & 1 & -1 & 1 & $-\alpha$ & $+\alpha$ & $\mathbf{0}$ & $\mathbf{0}$ & 0 \\
\hline & B & -1 & -1 & 1 & 1 & 0 & 0 & $-\alpha$ & $+\alpha$ & 0 \\
\hline $\begin{array}{c}\text { Mixture } \\
\text { component }\end{array}$ & $\begin{array}{c}\text { Sample } \\
\text { label }\end{array}$ & 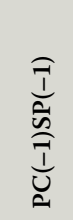 & 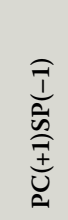 & 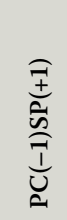 & 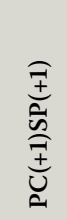 & 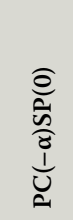 & 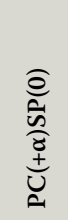 & $\frac{\delta}{i}$ & 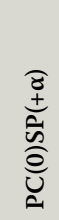 & $\begin{array}{l}\text { n } \\
\vdots \\
a \\
0 \\
0 \\
\hat{a} \\
0 \\
0 \\
0 \\
0\end{array}$ \\
\hline Cement & $\mathrm{kg} / \mathrm{m}^{3}$ & 321 & 434 & 319 & 430 & 296 & 455 & 380 & 375 & 378 \\
\hline Fly ash & $\mathrm{kg} / \mathrm{m}^{3}$ & 107 & 145 & 106 & 143 & 99 & 152 & 127 & 125 & 126 \\
\hline Silica fume & $\mathrm{kg} / \mathrm{m}^{3}$ & 26 & 35 & 26 & 35 & 24 & 37 & 31 & 30 & 31 \\
\hline Water & $\mathrm{kg} / \mathrm{m}^{3}$ & 159 & 215 & 158 & 213 & 147 & 225 & 188 & 186 & 187 \\
\hline Coarse aggregate & $\mathrm{kg} / \mathrm{m}^{3}$ & 784 & 784 & 784 & 784 & 784 & 784 & 784 & 784 & 784 \\
\hline Fine aggregate & $\mathrm{kg} / \mathrm{m}^{3}$ & 1067 & 764 & 1064 & 764 & 1130 & 702 & 910 & 910 & 909 \\
\hline SP dosage & $\%$ & 0.39 & 0.39 & 1.11 & 1.11 & 0.75 & 0.75 & 0.28 & 1.26 & 0.75 \\
\hline
\end{tabular}

\section{Table 4 Mix designs of Set 2}

\begin{tabular}{|l|c|c|c|c|c|c|}
\hline \multirow{2}{*}{$\begin{array}{c}\text { Mixture } \\
\text { components }\end{array}$} & & \multicolumn{5}{c|}{ Sample label } \\
\cline { 3 - 7 } & & PC25 & PC32 & PC43 & PC53 & PC60 \\
\hline Cement & $\mathrm{kg} / \mathrm{m}^{3}$ & 368 & 460 & 590 & 711 & 786 \\
\hline Fly ash & $\mathrm{kg} / \mathrm{m}^{3}$ & 66 & 83 & 106 & 128 & 142 \\
\hline Silica fume & $\mathrm{kg} / \mathrm{m}^{3}$ & 55 & 69 & 89 & 107 & 118 \\
\hline Water & $\mathrm{kg} / \mathrm{m}^{3}$ & 144 & 180 & 231 & 279 & 308 \\
\hline Coarse aggregate & $\mathrm{kg} / \mathrm{m}^{3}$ & 998 & 972 & 935 & 900 & 879 \\
\hline Fine aggregate & $\mathrm{kg} / \mathrm{m}^{3}$ & 936 & 735 & 452 & 191 & 27 \\
\hline Superplasticiser & $\mathrm{kg} / \mathrm{m}^{3}$ & 7.36 & 7.16 & 6.89 & 6.64 & 6.48 \\
\hline Paste content & $\%$ & 24.9 & 31.9 & 42.5 & 53.0 & 60.0 \\
\hline SP dosage & $\%$ & 1.50 & 1.17 & 0.88 & 0.70 & 0.62 \\
\hline
\end{tabular}

\section{Test methods to determine fresh and hydration properties}

The flow table test for concrete was used to determine the workability of the concrete tested. The test was conducted according to BS 1881-105:1984 (BS 1881 1984). The flow was reported to the nearest $10 \mathrm{~mm}$.

To obtain an indication of temperature rise during hydration, semi-adiabatic calorimetry was used. A fresh concrete sample was placed in a plastic container and a thermocouple was embedded in the sample. The plastic container was then placed inside a Dewar flask and sealed. The starting temperature of the samples was $20 \pm 2^{\circ} \mathrm{C}$, while the environmental temperature was $25^{\circ} \mathrm{C}$. The temperature rise was measured for 24 hours. Identical plastic containers of $300 \mathrm{ml}$ were used for each mixture that was tested. The containers were completely filled, thus the same volume of concrete was tested each time.
The maximum temperature was extracted from the temperature rise curve.

\section{Test methods to determine mechanical properties}

The compressive strength of the concrete was

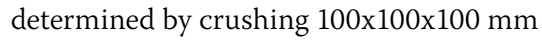
cubes according to SANS 5863:2006 (SANS 5863 2006). The cubes tested after 24 hours were tested directly after demoulding. The air-cured cubes were tested without submerging them in water before testing. This was done to determine the in-situ strength.

The modulus of rupture (MOR) or flexural strength was tested according to SANS 5864:2006 (SANS 5864 2006). The beam dimensions were $100 \times 100 \times 500 \mathrm{~mm}$. The supports were $300 \mathrm{~mm}$ apart and the loads were applied at two points, $50 \mathrm{~mm}$ from the middle of the beam. To determine the split cylinder strength, samples were tested according to ASTM C496/C496M-11:2004
(ASTM C496 2004). The method provides an indirect tensile strength value.

\section{Test methods to determine deformation properties}

The total early-age deformation (consisting of settlement and autogenous shrinkage) was determined using the shrinkage cone method proposed by Eppers (2010) and Kaufmann et al (2004). The size of the cone was adjusted for the measurement of concrete containing $9.5 \mathrm{~mm}$ aggregate. The deformation was measured using a high-accuracy laser with a range of $2 \mathrm{~mm}$. The cone mould was manufactured from aluminium. Teflon was used to line the inside of the cone mould, ensuring that friction did not hamper the measured deformation. To prevent drying shrinkage the procedure was conducted at $99 \%$ relative humidity. The temperature of the samples was measured while the deformation was monitored. The temperature of the samples did not rise beyond room temperature, which confirmed that the early-age deformation was not influenced by temperature variation. The small sample size allows sufficient heat dissipation to prevent temperature rise.

The fresh concrete was placed in the mould in two layers. Each layer was vibrated to ensure adequate compaction. The thermocouple was embedded during the vibration process. After the concrete had been placed, a reflector was positioned in the centre of the sample. The initial length of the concrete sample was determined with a Vernier calliper. The cone mould with the concrete and reflector was then inserted in the rig on which the laser was mounted. The position of the laser was adjusted so that shrinkage and swelling could be measured. The deformation of the concrete was logged every two minutes for 24 hours.

The total long-term deformation of the CCD concrete was determined using 50x50x300 mm prisms. The effective length of the prisms was $255 \mathrm{~mm}$. The first measurement was taken 24 hours after casting. Subsequent readings were taken after seven days and after 28 days. No initial wet curing was administered. The orientation at which the samples were stored at $55 \%$ relative humidity remained constant throughout the experimental programme.

The modulus of elasticity as represented by the secant modulus was determined according to ASTM C469/C469M-14:2002 (ASTM C469 2002). Concrete cylinders of $150 \mathrm{~mm}$ diameter and $300 \mathrm{~mm}$ length were tested. The strain measuring equipment was fitted to the specimen before placing it inside the loading machine. The specimens were loaded at a steady rate of $270 \mathrm{kPa} / \mathrm{s}$. The strain was measured at three points up to $40 \%$ of the 
Table 5 General linear ANOVA for selected measured responses

\begin{tabular}{|c|c|c|c|c|c|c|c|c|c|}
\hline & & \multirow{2}{*}{$\begin{array}{l}\text { Dependent } \\
\text { variable }\end{array}$} & \multirow{2}{*}{$\begin{array}{l}\text { Source of } \\
\text { variation }\end{array}$} & \multirow[b]{2}{*}{ DOF } & \multicolumn{3}{|c|}{ Statistical parameters } & \multirow{2}{*}{$\begin{array}{c}\text { Significant } \\
\mathrm{p}<0.05\end{array}$} & \multirow{2}{*}{$\begin{array}{c}\text { Contribution } \\
(\%)\end{array}$} \\
\hline & & & & & $\begin{array}{l}\text { Sum of } \\
\text { squares }\end{array}$ & $\mathbf{F}$ & p-value & & \\
\hline Fresh properties & N/A & Flow table & $\begin{array}{l}\text { Paste content } \\
\text { SP dosage }\end{array}$ & $\begin{array}{l}1 \\
1\end{array}$ & $\begin{array}{l}215500 \\
159700\end{array}$ & $\begin{array}{l}29.24 \\
21.67\end{array}$ & $\begin{array}{l}0.0003 \\
0.0009\end{array}$ & $\begin{array}{l}\mathrm{Y} \\
\mathrm{Y}\end{array}$ & $\begin{array}{l}57.44 \\
42.56\end{array}$ \\
\hline Hydration properties & $\begin{array}{c}\text { Early-age - } \\
24 \text { hours }\end{array}$ & $\begin{array}{l}\text { Maximum } \\
\text { temperature }\end{array}$ & $\begin{array}{l}\text { Paste content } \\
\text { SP dosage }\end{array}$ & $\begin{array}{l}1 \\
1\end{array}$ & $\begin{array}{c}44.18 \\
3.7\end{array}$ & $\begin{array}{l}31.91 \\
2.67\end{array}$ & $\begin{array}{l}0.0002 \\
0.1332\end{array}$ & $\begin{array}{l}\mathrm{Y} \\
\mathrm{N}\end{array}$ & $\begin{array}{l}92.27 \\
7.73\end{array}$ \\
\hline \multirow{4}{*}{ Mechanical properties } & \multirow{2}{*}{$\begin{array}{c}\text { Early-age - } \\
24 \text { hours }\end{array}$} & $\begin{array}{l}\text { Compressive } \\
\text { strength }\end{array}$ & $\begin{array}{l}\text { Paste content } \\
\text { SP dosage }\end{array}$ & $\begin{array}{l}1 \\
1\end{array}$ & $\begin{array}{r}27.96 \\
145.84\end{array}$ & $\begin{array}{c}2.16 \\
11.26\end{array}$ & $\begin{array}{l}0.1726 \\
0.0073\end{array}$ & $\begin{array}{l}\mathrm{N} \\
\mathrm{Y}\end{array}$ & $\begin{array}{l}16.09 \\
83.91\end{array}$ \\
\hline & & $\begin{array}{l}\text { Modulus of } \\
\text { rupture }\end{array}$ & $\begin{array}{l}\text { Paste content } \\
\text { SP dosage }\end{array}$ & $\begin{array}{l}1 \\
1\end{array}$ & $\begin{array}{l}0.18 \\
1.21\end{array}$ & $\begin{array}{l}0.43 \\
2.97\end{array}$ & $\begin{array}{l}0.5266 \\
0.1156\end{array}$ & $\begin{array}{l}\mathrm{N} \\
\mathrm{N}\end{array}$ & $\begin{array}{l}12.95 \\
87.05\end{array}$ \\
\hline & \multirow{2}{*}{$\begin{array}{l}\text { Long-term - } \\
28 \text { days }\end{array}$} & $\begin{array}{l}\text { Compressive } \\
\text { strength }\end{array}$ & $\begin{array}{l}\text { Paste content } \\
\text { SP dosage }\end{array}$ & $\begin{array}{l}1 \\
1\end{array}$ & $\begin{array}{l}5.56 \\
0.13\end{array}$ & $\begin{array}{l}0.15 \\
3410\end{array}$ & $\begin{array}{l}0.7052 \\
0.9546\end{array}$ & $\begin{array}{l}\mathrm{N} \\
\mathrm{N}\end{array}$ & $\begin{array}{l}97.72 \\
2.28\end{array}$ \\
\hline & & $\begin{array}{l}\text { Modulus of } \\
\text { rupture }\end{array}$ & $\begin{array}{l}\text { Paste content } \\
\text { SP dosage }\end{array}$ & $\begin{array}{l}1 \\
1\end{array}$ & $\begin{array}{l}0.1 \\
0.6\end{array}$ & $\begin{array}{l}0.19 \\
1.13\end{array}$ & $\begin{array}{l}0.6707 \\
0.3122\end{array}$ & $\begin{array}{l}\mathrm{N} \\
\mathrm{N}\end{array}$ & $\begin{array}{l}14.29 \\
85.71\end{array}$ \\
\hline \multirow{2}{*}{ Deformation properties } & $\begin{array}{l}\text { Early-age - } \\
24 \text { hours }\end{array}$ & $\begin{array}{c}\text { Total } \\
\text { deformation }\end{array}$ & $\begin{array}{l}\text { Paste content } \\
\text { SP dosage }\end{array}$ & $\begin{array}{l}1 \\
1\end{array}$ & $\begin{array}{c}2806000 \\
32644\end{array}$ & $\begin{array}{c}101.24 \\
1.18\end{array}$ & $\begin{array}{l}0.0001 \\
0.3138\end{array}$ & $\begin{array}{l}\mathrm{Y} \\
\mathrm{N}\end{array}$ & $\begin{array}{l}98.85 \\
1.149\end{array}$ \\
\hline & $\begin{array}{l}\text { Long-term - } \\
28 \text { days }\end{array}$ & $\begin{array}{c}\text { Total } \\
\text { deformation }\end{array}$ & $\begin{array}{l}\text { Paste content } \\
\text { SP dosage }\end{array}$ & $\begin{array}{l}1 \\
1\end{array}$ & $\begin{array}{c}1294.37 \\
272.91\end{array}$ & $\begin{array}{c}0.2 \\
0.042\end{array}$ & $\begin{array}{l}0.6646 \\
0.8416\end{array}$ & $\begin{array}{l}\mathrm{N} \\
\mathrm{N}\end{array}$ & $\begin{array}{l}82.59 \\
17.41\end{array}$ \\
\hline
\end{tabular}

failure load of the concrete. This test method is non-destructive and the same samples were also used to determine the splitting strength.

A variation of ASTM C512/C512M10:2002 (ASTM C512 2002) was used to measure the load-induced time-dependent compressive strain (or creep) of concrete. Cylindrical samples with a diameter of $80 \mathrm{~mm}$ and a length of $300 \mathrm{~mm}$ were used. The samples were subjected to $3 \mathrm{MPa}, 24$ hours after casting. This load was selected to represent environmental loads. The load was maintained for the 90 days that the creep was measured. Two targets were attached $200 \mathrm{~mm}$ apart on each side of each sample. An extensometer was used to determine the length change. For each mixture two samples were loaded to measure load-induced deformation, and one sample was used to measure all other deformation (such as drying shrinkage) that the concrete might experience. This value was reported as the total long-term deformation. Creep was calculated by subtracting the longterm deformation of the unloaded samples from the deformation of the loaded samples.

\section{RESULTS AND DISCUSSION}

\section{GLM-ANOVA}

The GLM-ANOVA of the tested responses can be seen in Table 5. Only the fresh and some of the early-age properties were affected by the varied parameters. Both paste content and SP dosage have a significant effect on the

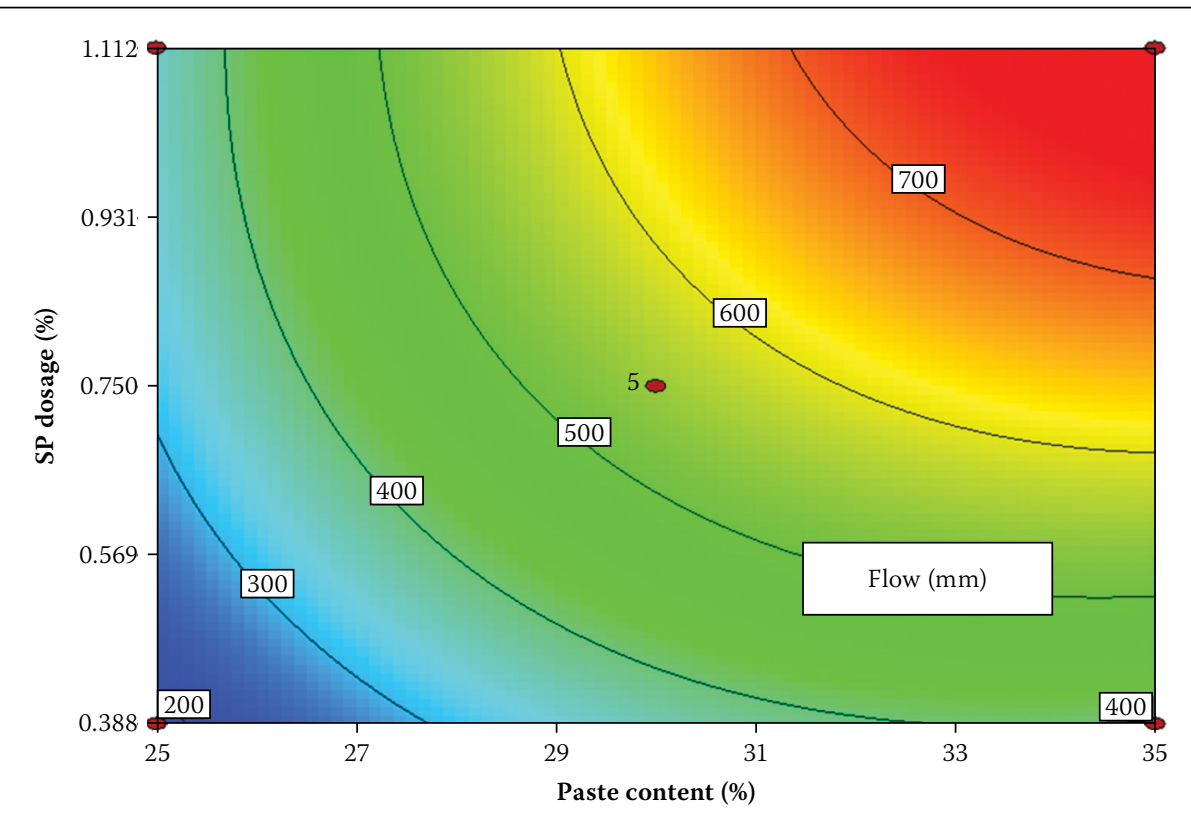

\section{Figure 6 Contour plot of flow of Set 1}

flow of the HSC. The percentage contribution also shows that both parameters are equally effective in controlling the response. This result confirms that workability can be controlled by paste content and SP dosage.

According to the GLM-ANOVA, paste content controlled the maximum temperature reached under semi-adiabatic conditions. The effect of paste content on the 24-hour compressive strength was less significant than the effect of SP dosage. The paste content influenced the total early-age deformation dominantly, where Holt (2001) found that SP dosage should also influence it significantly. The other properties, i.e. MOR, long-term compressive strength and long-term total deformation in Table 5 were not affected by the paste content in the range that was tested. The GLM-ANOVA also showed that the SP dosage did not affect these properties either, as expected.

\section{Fresh properties}

Figure 6 shows the response surface of flow. The response surface confirms that both paste content and SP dosage influence the 
workability of HSC to the same extent. When looking at the spacing between the contour lines diagonally, it can be seen that the flow increases faster at lower percentages of the constituents. The improvement of flow flattens out towards the higher paste content and SP dosage.

\section{Hydration properties}

Figure 7 shows that the maximum temperature reached under semi-adiabatic conditions has a positive correlation to the paste content. The SP dosage seemed to decrease the maximum temperature reached at specific paste content. This could be due to a retardation effect, where the combination of the retardation of heat generation and heat dissipation impedes high maximum temperatures.

The maximum temperature tested for Set 2 reached similar values to that of Set 1 for paste content of $25 \%$ to $35 \%$ (between $35^{\circ} \mathrm{C}$ and $45^{\circ} \mathrm{C}$ ). Surprisingly, the higher SF addition percentage (5.7\% for Set 1 in comparison to $11.2 \%$ for Set 2) did not increase the maximum temperature. Figure 8 shows that temperatures up to $70^{\circ} \mathrm{C}$ can be reached with paste contents of $60 \%$. The hazardous consequence, in terms of heat of hydration, of significantly increasing the paste content is evident.

\section{Mechanical properties}

In the range tested for paste content and SP dosage, the compressive strength was influenced more significantly by the SP dosage (as indicated by the GLM-ANOVA). The contour plot showed in Figure 9 shows that the highest early-age strength can be achieved when the lowest paste content and SP dosage is used. The workability of such a concrete mix would be impractically low.

Figure 10 shows the effect of paste content on the compressive strength as well as strength development of concrete. The paste content clearly affected the early-age strength by increasing it at paste content percentages higher than $35 \%$. The range of Set 1 was too small to observe this effect. Stock et al (1979) also showed that compressive strength exhibits a minimum in the range between $30 \%$ and $50 \%$ paste content.

Approximately $40 \mathrm{MPa}$ can be obtained at $60 \%$ paste content 24 hours after casting. The compressive strength difference between the respective concretes decreased with time. After three days the benefits of using high paste content for compressive strength are already negligible. At 56 days the compressive strength had a negative correlation to paste content increase, which leads to the conclusion that curing conditions affect the high paste content concretes more

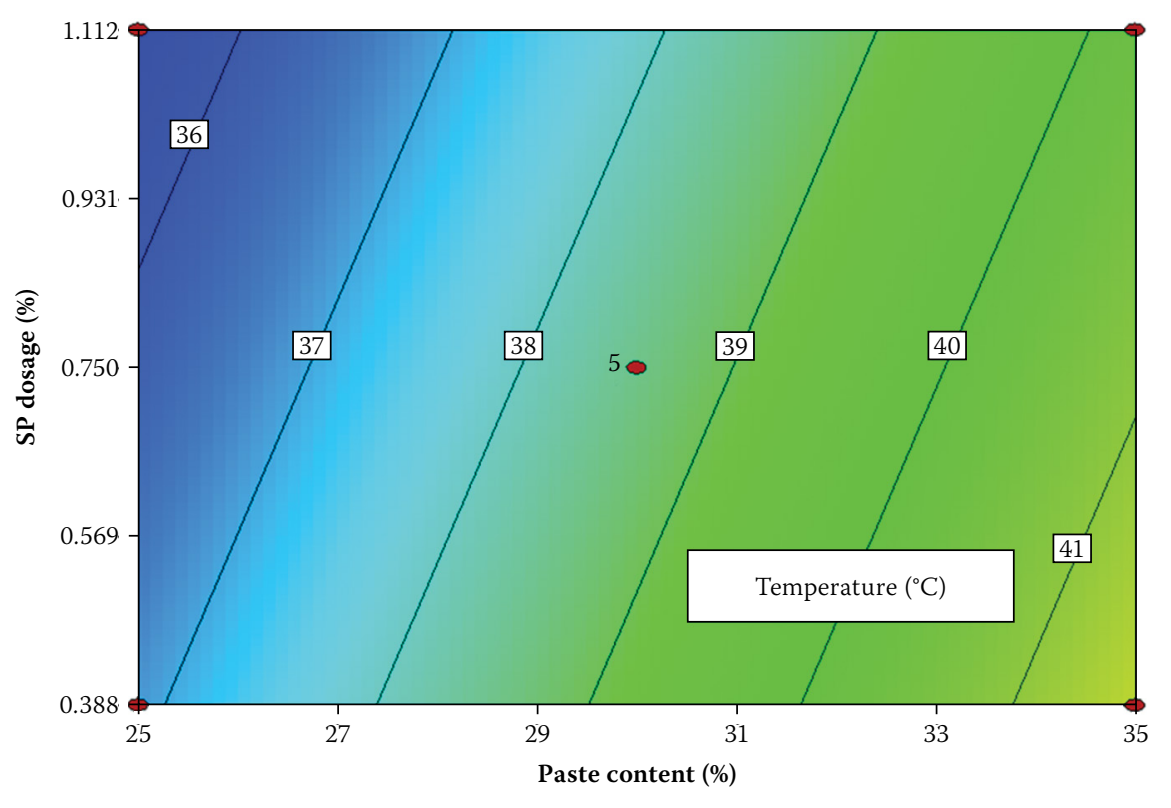

Figure 7 Contour plot of the maximum temperature of Set 1

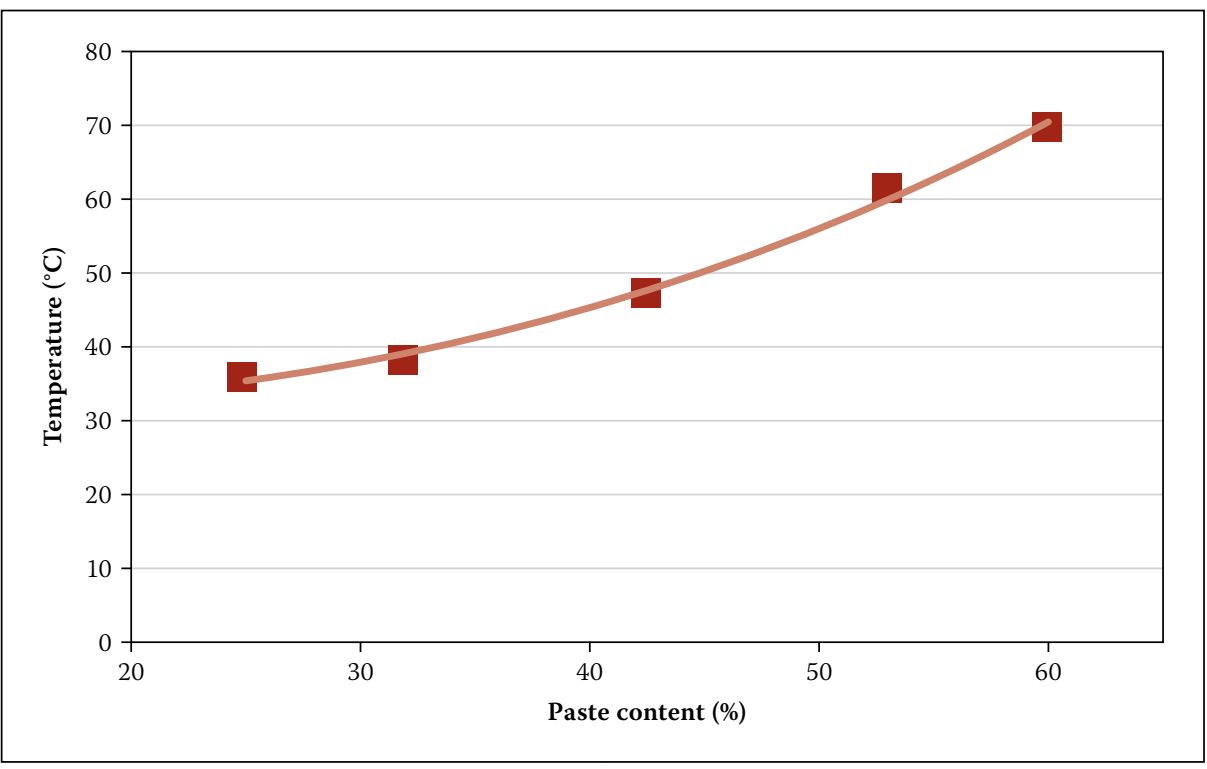

Figure 8 Maximum temperatures of Set 2

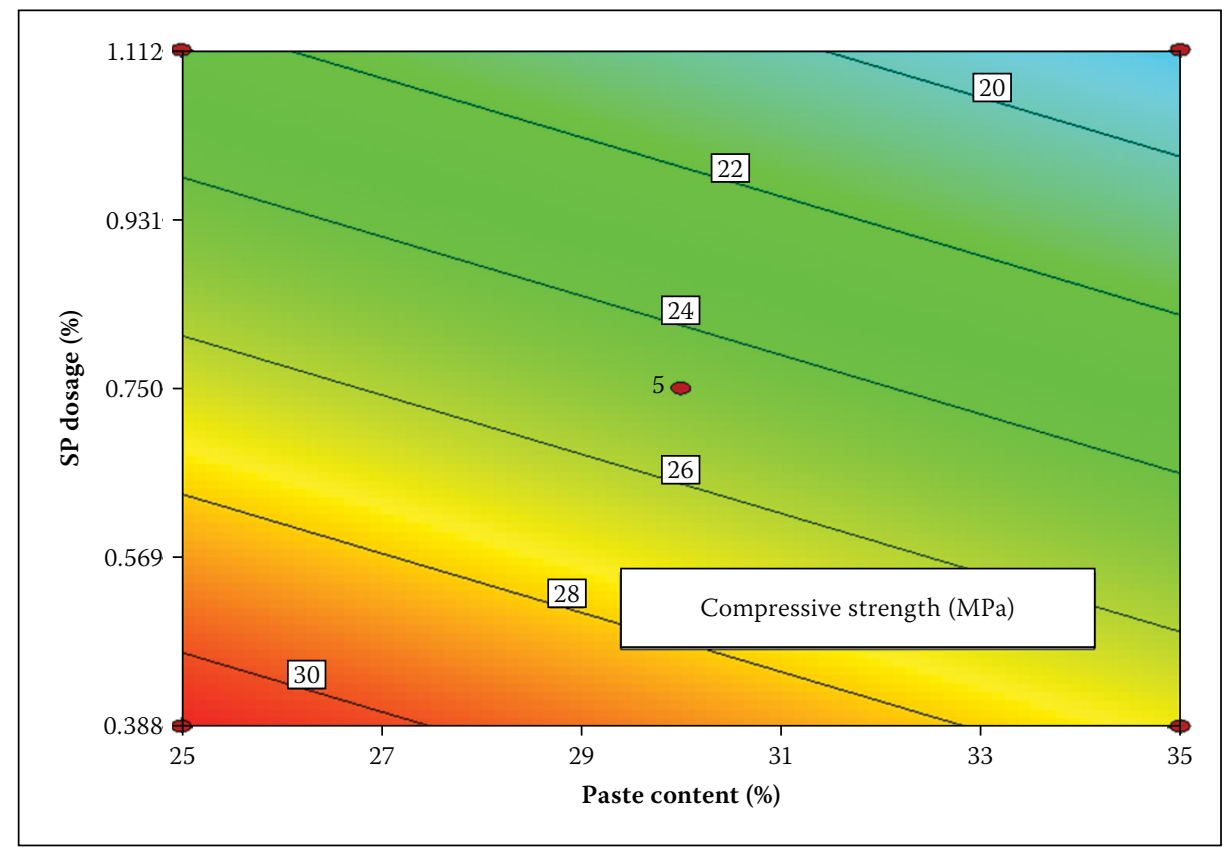

Figure 9 Contour plot of compressive strength of Set 1 


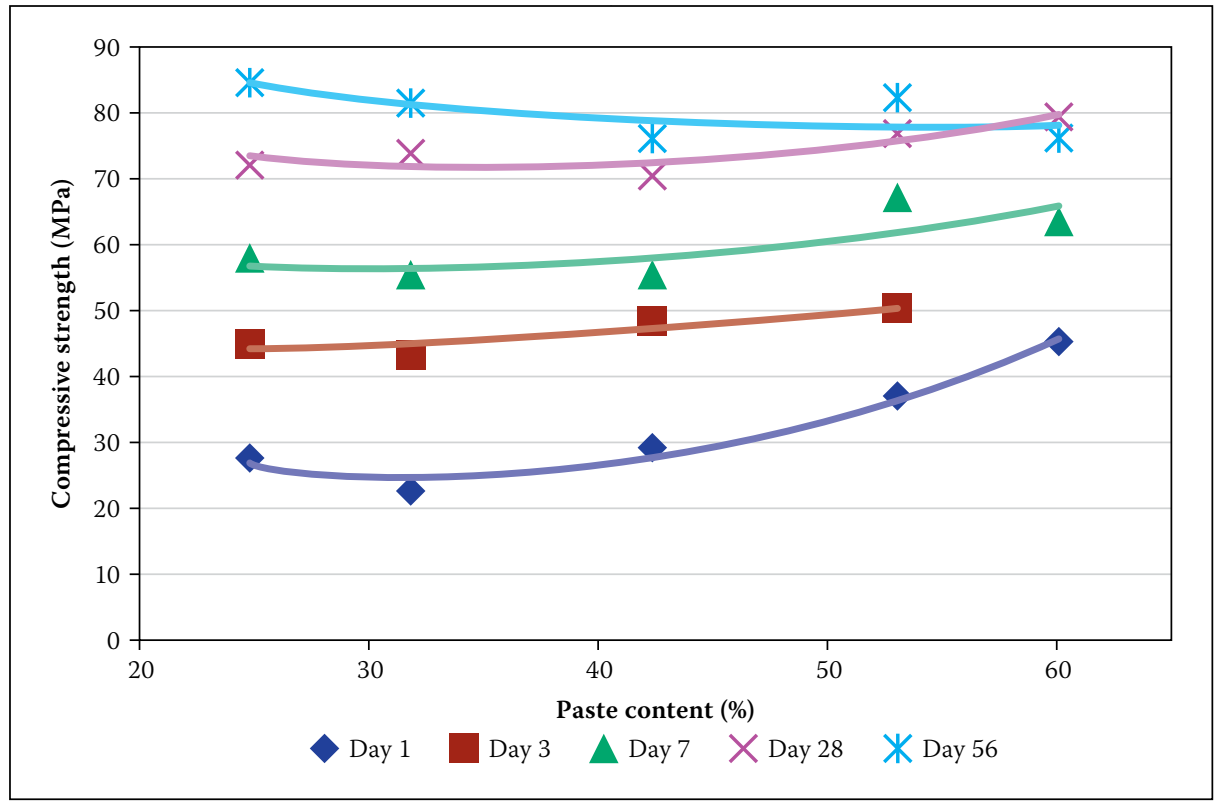

Figure 10 Compressive strength of Set 2

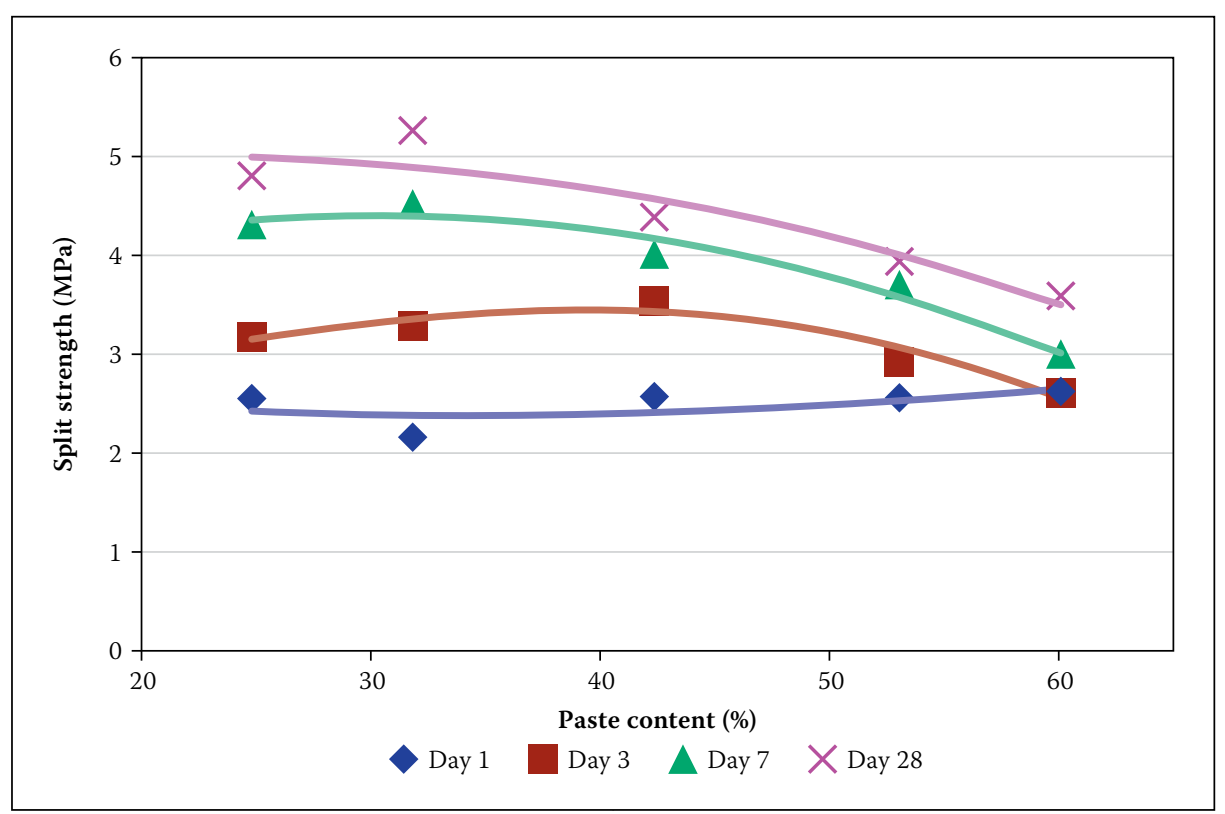

Figure 11 Indirect tensile strength of Set 2

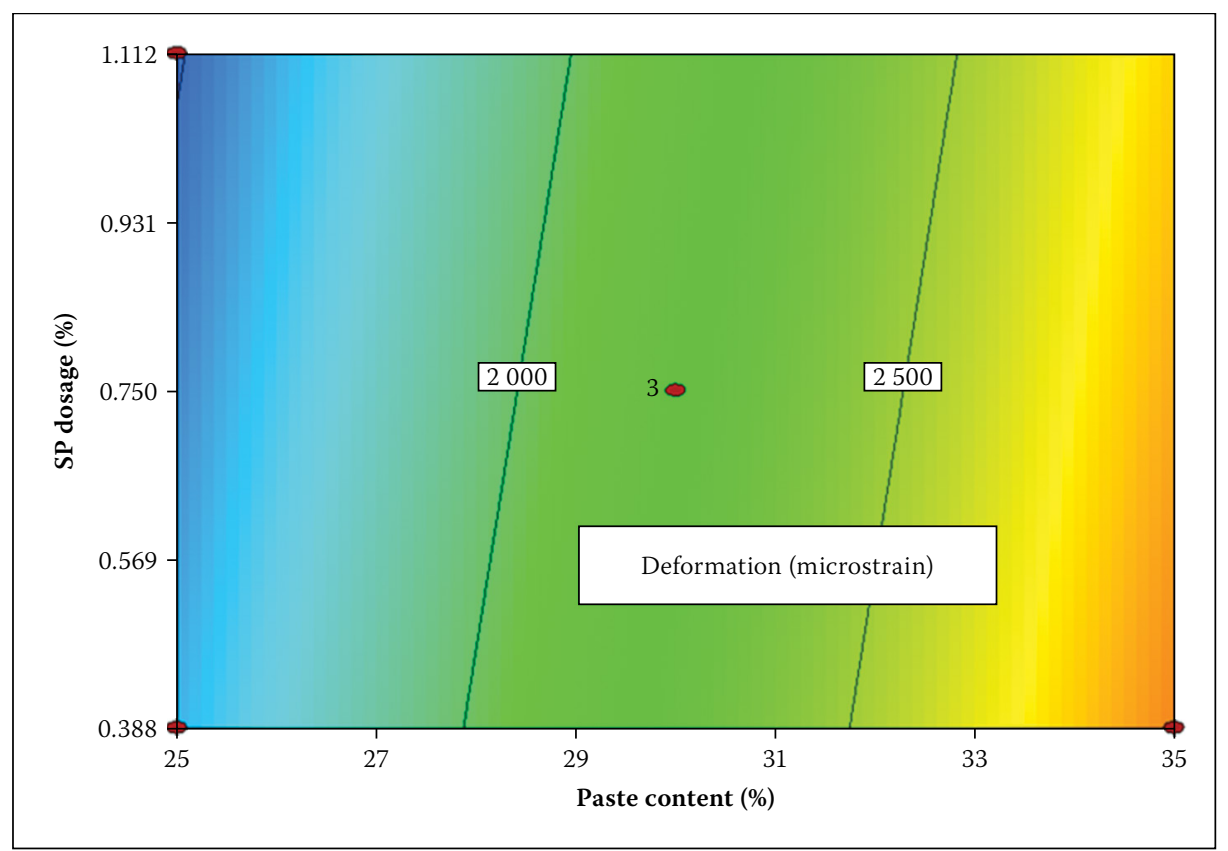

Figure 12 Contour plot of total early-age deformation of Set 1 significantly. More severe curing conditions than $99 \%$ relative humidity and $25^{\circ} \mathrm{C}$ would likely have a more detrimental effect.

The statistical analysis of the Set 1 results showed that the MOR is not influenced by SP dosage or paste content in the range that was tested. In Figure 11 the split cylinder strength tested for Set 2 was unaffected by paste content after 24 hours. Paste content did, however, decrease the indirect tensile strength at later ages, making it clear that high paste content can decrease the tensile strength of concrete, leading to crack formation at later ages at lower stresses.

\section{Deformation properties}

The total early-age deformations include all movements measured with the shrinkage cone method. Although the setup was devised to measure the autogenous shrinkage, it was impossible to determine the transition between plastic and hardened phase. The total early-age deformation includes the settlement and autogenous shrinkage. Note that the positive values signify contraction.

Figure 12 shows that, by increasing the paste content, the total early-age deformation is increased. For a given paste content, an increase in superplasticiser dosage results in a marginal decrease in total early-age deformation. This contradicts the findings by Holt (2005) where the addition of superplasticiser increased the autogenous shrinkage.

In Figure 13 the total early-age deformation also increases as the paste content increases. The magnitude of deformation of Set 1 and Set 2 in the 25\% to 35\% range was similar between 1500 microstrain and 2500 microstrain. At $60 \%$ paste content a total early-age deformation of approximately 3800 microstrain was recorded.

Even though some of the deformation occurs before stress can be induced, these values give an indication of the effect of paste content on the volume stability and cracking potential of the concrete. By minimising the paste content of concrete used in UTCRCP, early-age cracking can be prevented or at least minimised by preventing excessive shrinkage during the first 24 hours. In addition SP dosage may decrease early-age deformation. If early-age deformation in the same order of magnitude were to occur in UTCRCP, significant stresses would be induced if the concrete body is restrained.

The total long-term deformation of Set 1 did not produce a statistically relevant model. After 120 days at $55 \% \mathrm{RH}$ and $25^{\circ} \mathrm{C}$ Set 2 contracted up to approximately 350 microstrain for $60 \%$ paste content as seen in Figure 14. Note that the deformation reported excludes the early-age deformation. As expected, the paste content increased 
the deformation significantly from 125 microstrain at $25 \%$ to 350 microstrain at $60 \%$.

The modulus of elasticity decreased as the paste content increased. Figure 15 shows that this trend remained unchanged, even as the paste gained strength. Paste content had a significant effect on the stiffness of concrete.

As with the shrinkage deformation, the creep strain of Set 2 increased as the paste content increased. Similarly to the modulus of elasticity, the paste in the concrete deforms more than the aggregate. Figure 16 shows that the creep increases as the paste content increases. The creep increased significantly from 63 microstrain for $25 \%$ paste content to 420 microstrain for $60 \%$ paste content.

The effect of the paste content on the modulus of elasticity and creep of HSC is not necessarily undesirable for concrete pavement applications. A lower modulus of elasticity allows the concrete to deform without generating high stresses and the high creep allows the concrete to relax under stress, thus alleviating stress. Further research is required to determine whether there is an optimum paste content that minimises the cracking tendency.

\section{CONCLUSIONS AND RECOMMENDATIONS}

No statistically valid long-term property models could be developed using RSM for the first set of concrete, while Set 2 clearly showed that paste content does affect compressive strength, tensile strength, long-term shrinkage, modulus of elasticity and creep. It was not possible to extend the range of Set 1 over the same range that was used for Set 2 , because all concrete mixes cast for Set 1 had to be practical (they must not be too dry to compact or contain such a high SP dosage that the concrete segregates). Set 2 was designed to be practical, and the SP dosage and paste content were varied at the same time.

The volume stability of concrete is severely affected by paste content, and high paste content will contribute to high strains throughout the lifetime of the concrete pavement. By using high paste content, pavements are subjected to high maximum temperatures during hydration, causing the pavement to contract more when it returns to ambient conditions, inducing higher tensile stresses.

Paste content can be used to obtain high early strength if it is increased to more than $35 \%$ of the concrete mass. The heat of hydration will be increased by doing this and the higher compressive strength is almost

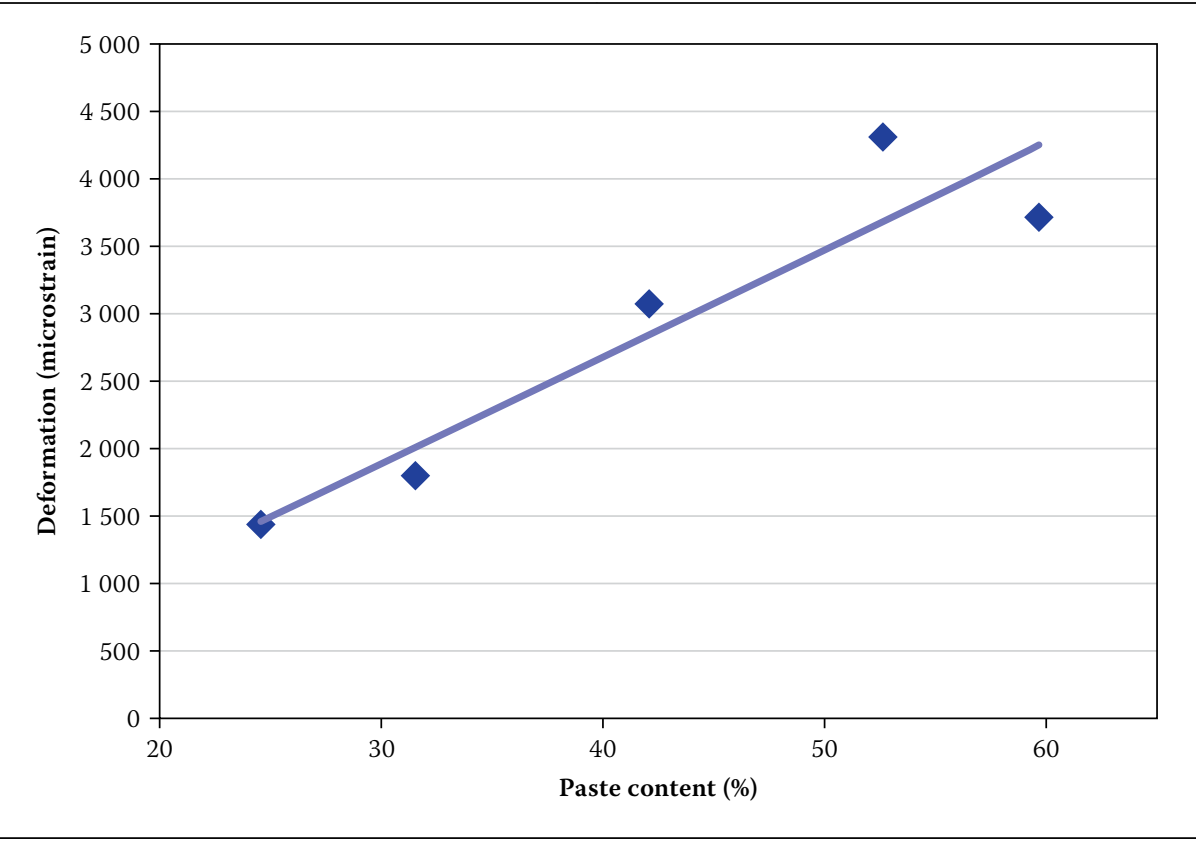

Figure 13 Total early-age deformation of Set 2

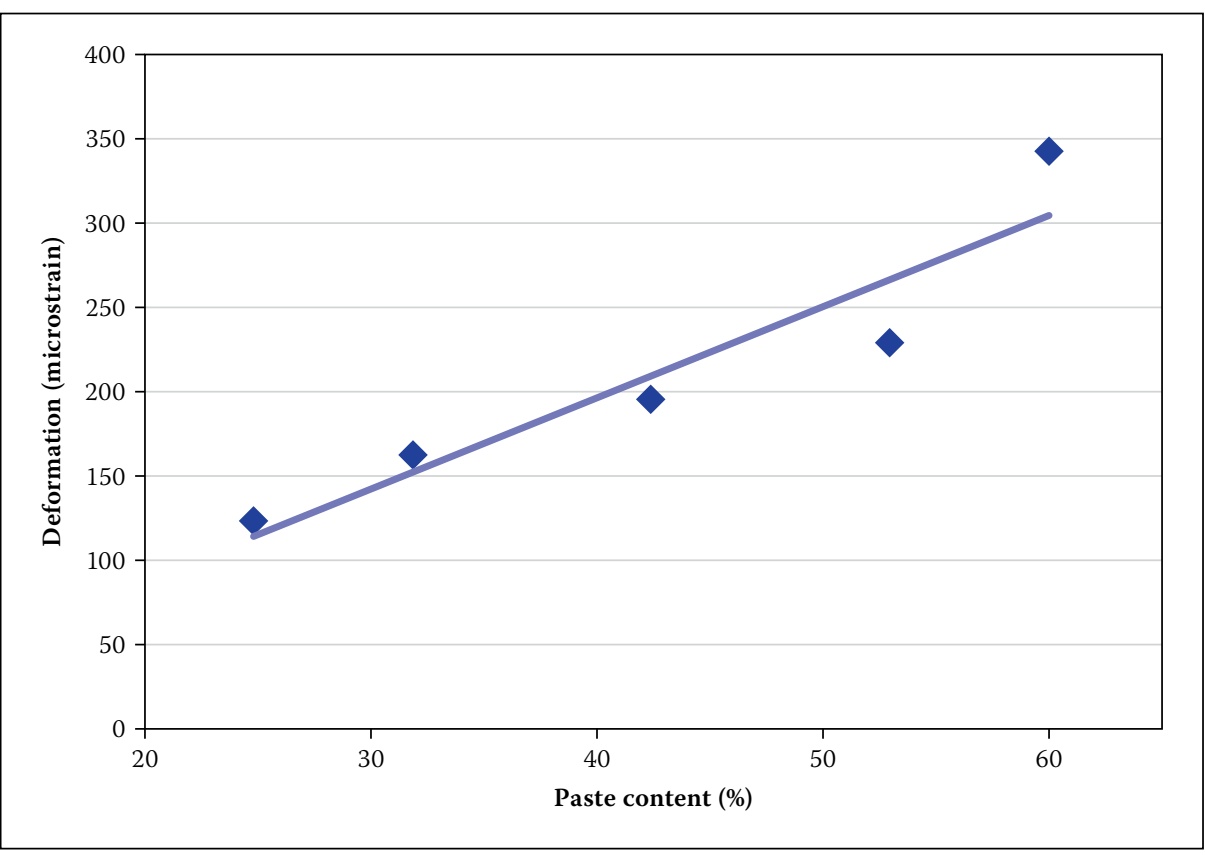

Figure 14 Total long-term deformation of Set 2

negligible after only three days. High paste content has a detrimental effect on the tensile strength of concrete, which can lead to crack formation at lower strains. In terms of concrete pavement application, paste content does, however, have a beneficial effect where it decreases the modulus of elasticity and increases the creep. The internal stresses in restrained UTCRCP could be reduced in this manner. The overall effect of paste content on the tendency of HSC to crack should be investigated.

Awareness of the side-effects of high paste content is essential. To ensure that UTCRCP does not fail prematurely it would be advisable to minimise the paste content, while maintaining reasonable workability. Ultimately, concrete mixture proportions can be optimised to minimise cracking tendency by determining the effect of mixture constituents on the relevant properties, using RSM and incorporating a mechanistic model to evaluate the cracking tendency.

\section{REFERENCES}

Alves, M F, Cremonini, R A \& Dal Molin, D C C 2004 A comparison of mix proportioning methods for high-strength concrete. Cement and Concrete Composites, 26(6): 613-621.

ASTM C496/C496M-11 2004. Standard Test Method for Splitting Tensile Strength of Cylinder Concrete Specimens. West Conshohocken, PA, US: ASTM. International.

ASTM Standard C469/C469M-14:2002. Standard

Test Method for Static Modulus of Elasticity and Poisson's Ratio of Concrete in Compression. West Conshohocken, PA, US: ASTM International. 


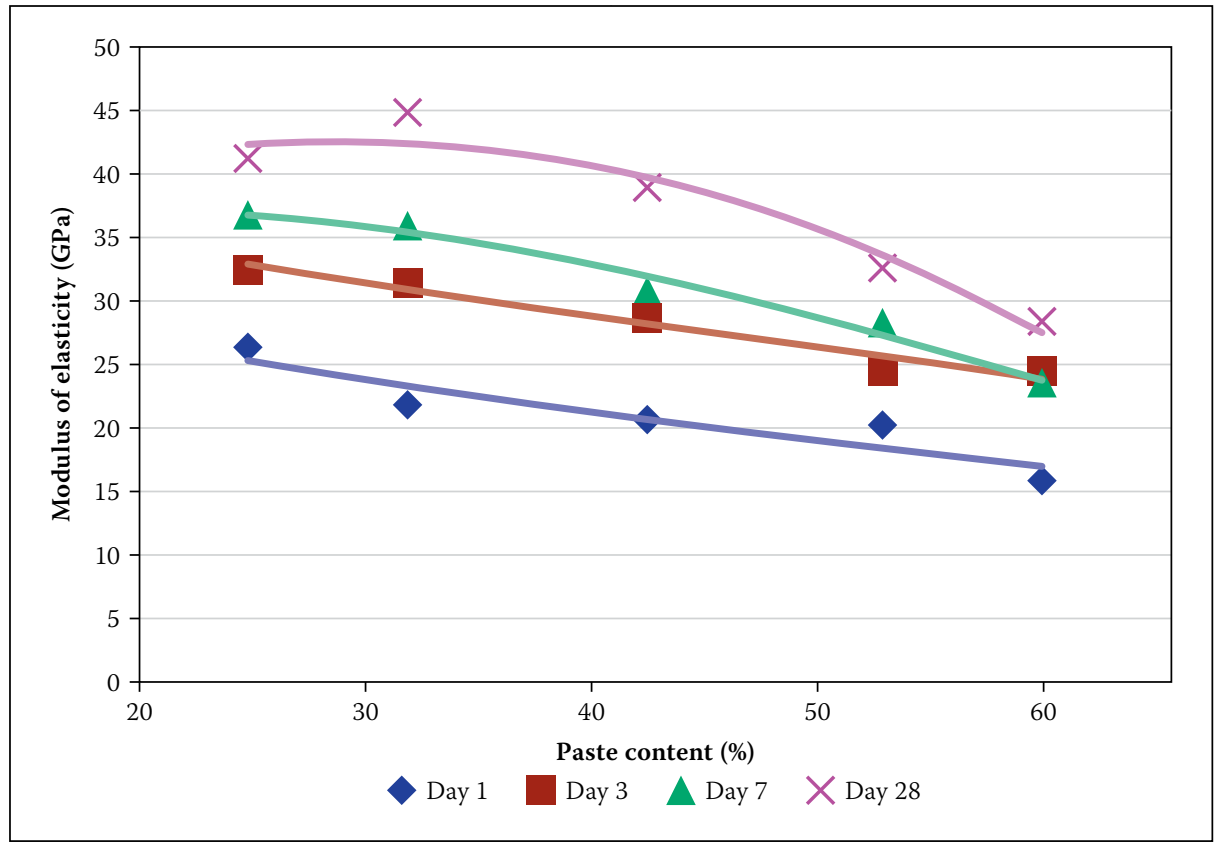

Figure 15 Modulus of elasticity of Set 2

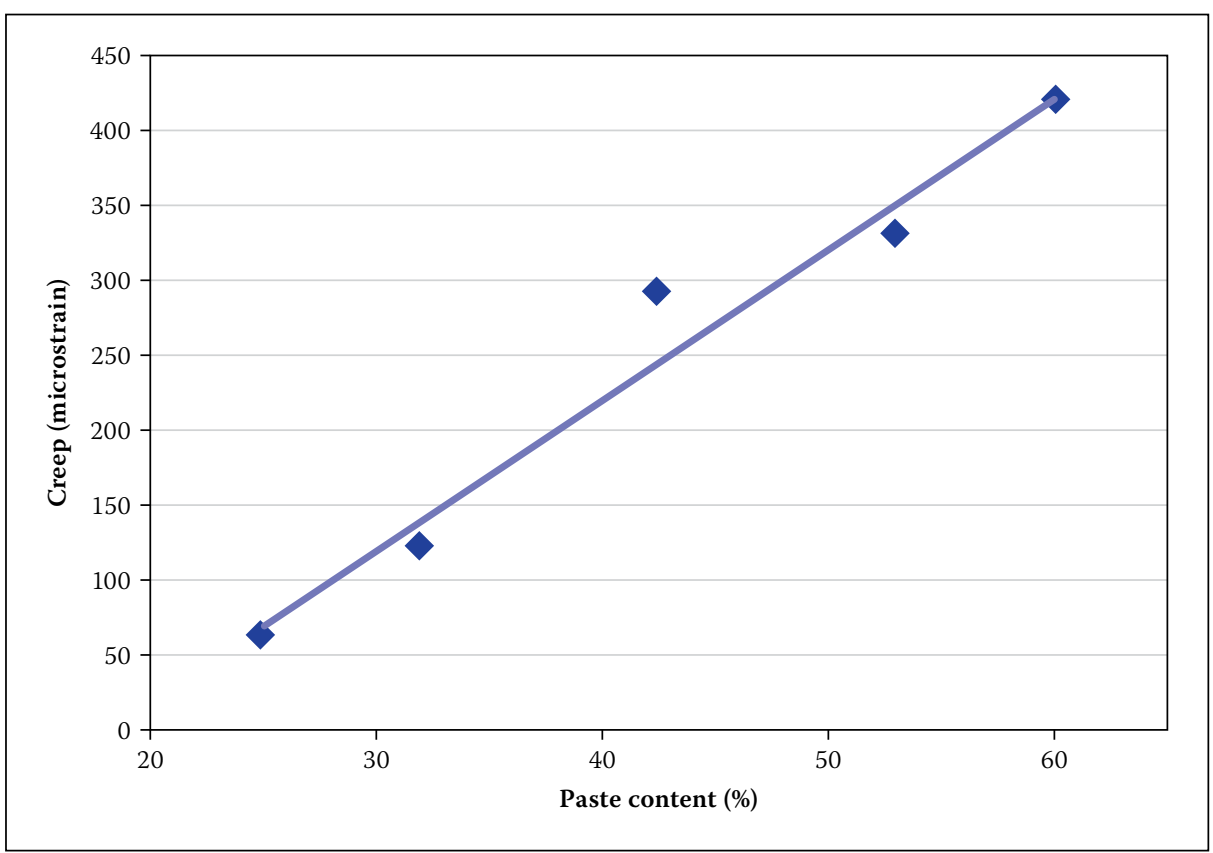

\section{Figure 16 Creep of Set 2}

ASTM Standard C512/C512M-10:2002. Standard Test Method for Creep of Concrete in Compression. West Conshohocken, PA, US: ASTM International.

Bentz, D P, Hansen, A S \& Guynn, J M 2011.

Optimization of cement and fly ash particle sizes to produce sustainable concretes. Cement and Concrete Composites, 33(8): 824-831.

BS 1881 - 105:1984. Testing concrete. Part 105: Method for Determination of Flow, London: British Standards Institution.

Domone, P \& Illston, J (Eds.) 2010. Construction Materials: Their Nature and Behaviour, 4th ed. London: Spon Press.

Eppers, S 2010. Assessing the autogenous shrinkage cracking propensity of concrete by means of the restrained ring test. Dissertation, Dresden, Germany: Technical University of Dresden.

Giussani, F \& Mola, F 2012. Durable concrete pavements: The reconstruction of runway head $36 \mathrm{R}$ fiber reinforcement on shrinkage, rheological and mechanical properties of Portland cement pastes. Cement and Concrete Composites, 26(5): 541-549.

Khokhar, M I A, Roziere, E, Turcry, P, Grondin, F \& Loukili, A 2010. Mix design of concrete with high content of mineral additions: Optimisation to improve early age strength. Cement and Concrete Composites, 32(5): 377-385.

Leemann, A, Lura, P \& Loser, R 2011. Shrinkage and creep of SCC - The influence of paste volume and binder composition. Construction and Building Materials, 25(5): 2283-2289.

Lotfy, A, Hossain, K M A \& Lachemi, M 2014. Application of statistical models in proportioning lightweight self-consolidating concrete with expanded clay aggregates. Construction and Building Materials, 65: 450-469.

Montgomery, D C 2001. Design and Analysis of Experiments, 5th ed. New York: Wiley.

Mukandila, E M W K, Milne, T I \& Horak, E 2009. Constructability aspects of ultra-thin continuously reinforced concrete pavement. Proceedings, 28th Southern African Transport Conference, Pretoria, pp 234-244.

Neville, A M 1995. Properties of Concrete, 4th ed. Harlow, UK: Longman Group.

Neville, A M \& Brooks, J J 2010. Concrete Technology, 2nd ed. Harlow, UK: Pearson.

Owens, G 2009. Fulton's Concrete Technology, 9th ed. Midrand: Cement \& Concrete Institute.

RILEM 1997. Recommendations of TC 119-TCE: Avoidance of thermal cracking in concrete at early ages. Materials and Structures, 30(202): 451-464.

SANRAL (South African National Roads Agency Limited) 2009. Implementation of Ultra-thin Continuously Reinforced Concrete Pavements. Pretoria: SANRAL.

SANRAL (South African National Roads Agency Limited) 2012. South African Pavement Engineering Manual, 1st ed. Pretoria: SANRAL.

SANS (South African National Standard) 2006. SANS 5863: 2006. Concrete Tests: Compressive Strength of Hardened Concrete. Pretoria: SABS Standards Division.

SANS (South African National Standard) 2006. SANS 5864: 2006 Concrete Tests: Flexural Strength of Hardened Concrete. Pretoria: SABS Standards Division.

Singh, B 1958. Specific surface of aggregates related to compressive and flexural strength of concrete. ACI Journal, Proceedings, 54(4): 897-907.

Stat-Ease Inc. 2014. Design-Expert ${ }^{\circ}$ Software for Design of Experiments. Minneapolis, MN, US: Stat=Ease Inc.

Stock, A, Hannant, D \& Williams, R 1979. The effect of aggregate concentration upon the strength and modulus of elasticity of concrete. Magazine of Concrete Research, 31(109): 225-234.

Zain, M F M, Islam, M N \& Basri, I H 2005. An expert system for mix design of high-performance concrete. Advances in Engineering Software, 36(5): 325-337. 